\title{
Potential mechanisms for lumbar spinal stiffness change following spinal manipulative therapy: a scoping review
}

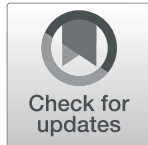

Peter Jun ${ }^{1}$ (D), Isabelle Pagé2 ${ }^{2}$, Albert Vette ${ }^{3}$ (D) and Greg Kawchuk ${ }^{4^{*}}$ (D)

\begin{abstract}
Introduction: In individuals having low back pain, the application of spinal manipulative therapy (SMT) has been shown to reduce spinal stiffness in those who report improvements in post-SMT disability. The underlying mechanism for this rapid change in stiffness is not understood presently. As clinicians and patients may benefit from a better understanding of this mechanism in terms of optimizing care delivery, the objective of this scoping review of current literature was to identify if potential mechanisms that explain this clinical response have been previously described or could be elucidated from existing data.
\end{abstract}

Methods: Three literature databases were systematically searched (MEDLINE, CINAHL, and PubMed). Our search terms included subject headings and keywords relevant to SMT, spinal stiffness, lumbar spine, and mechanism. Inclusion criteria for candidate studies were publication in English, quantification of lumbar spinal stiffness before and after SMT, and publication between January 2000 and June 2019.

Results: The search identified 1931 articles. Of these studies, 10 were included following the application of the inclusion criteria. From these articles, 7 themes were identified with respect to potential mechanisms described or derived from data: 1) change in muscle activity; 2) increase in mobility; 3) decrease in pain; 4) increase in pressure pain threshold; 5) change in spinal tissue behavior; 6) change in the central nervous system or reflex pathways; and 7) correction of a vertebral dysfunction.

Conclusions: This scoping review identified 7 themes put forward by authors to explain changes in spinal stiffness following SMT. Unfortunately, none of the studies provided data which would support the promotion of one theme over another. As a result, this review suggests a need to develop a theoretical framework to explain rapid biomechanical changes following SMT to guide and prioritize future investigations in this important clinical area.

Keywords: Low back pain, Lumbar spine, Manual therapy, Spinal manipulation, Spinal mobilization, Spinal stiffness

\footnotetext{
* Correspondence: greg.kawchuk@ualberta.ca

${ }^{4}$ Department of Physical Therapy, University of Alberta, Corbett Hall, 8205

114 Street NW, Edmonton, Alberta T6G 2G4, Canada

Full list of author information is available at the end of the article
}

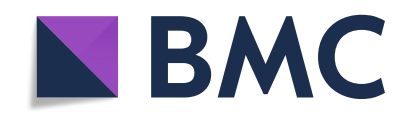

(c) The Author(s). 2020 Open Access This article is licensed under a Creative Commons Attribution 4.0 International License, which permits use, sharing, adaptation, distribution and reproduction in any medium or format, as long as you give appropriate credit to the original author(s) and the source, provide a link to the Creative Commons licence, and indicate if changes were made. The images or other third party material in this article are included in the article's Creative Commons licence, unless indicated otherwise in a credit line to the material. If material is not included in the article's Creative Commons licence and your intended use is not permitted by statutory regulation or exceeds the permitted use, you will need to obtain permission directly from the copyright holder. To view a copy of this licence, visit http://creativecommons.org/licenses/by/4.0/ The Creative Commons Public Domain Dedication waiver (http://creativecommons.org/publicdomain/zero/1.0/) applies to the data made available in this article, unless otherwise stated in a credit line to the data. 


\section{Introduction}

Low back pain (LBP) is the leading musculoskeletal cause of disability globally, while its financial burden continues to grow with an aging population $[1,2]$. One explanation for these statistics is that, in the majority of LBP cases, the specific nociceptive source of LBP cannot be identified [1,3]. As such, the treatment of nonspecific LBP when the cause is unknown can lead to a wide variety of outcomes if interventions cannot be matched to the underlying etiology $[4,5]$.

Spinal manipulative therapy (SMT) is a common mechanical conservative intervention for LBP that is recommended by several clinical practice guidelines and review papers [6-8]. Recently, a series of studies with small sample size have demonstrated that spinal biomechanics of individuals with LBP could change in those who receive SMT then report improvements in disability [9-11]. In these individuals, also called SMT responders, SMT resulted in local biomechanical changes including a rapid decrease in bulk stiffness and improvement in muscle contraction. The responders also displayed increased disc diffusion post-SMT; however, the disc diffusion was measured at a different time-point to the follow-up disability measure. In comparison, these same mechanical features did not change in individuals with LBP who were nonresponders to SMT. Importantly, a reduction in stiffness has been shown in two different studies $[9,10]$.

Taken together, these studies provide a unique investigative opportunity. Given that most interventions for LBP require weeks or months to exert their effect (e.g., exercise, surgery) [12] and few, if any, other interventions for LBP exhibit an association between self-reported and objective outcomes, this selective treatment response offers a novel starting point from which to identify a specific etiology of a subset of LBP. In addition, it may provide the opportunity to explore how a specific intervention may work to achieve this.

While the above development is unique in LBP research, it exists independently from an existing theoretical framework that would explain how the effects of SMT influence spinal stiffness and, ultimately, LBP in some, but not in other affected individuals. A theoretical framework is helpful for providing directions and priorities for future studies that would delineate the working mechanics of this phenomenon $[13,14]$. This new model could provide the basis to generate valuable knowledge in understanding the LBP source and how it may be targeted with specific therapeutic interventions in the future.

With this in mind, we conducted a scoping review with the objective of identifying existing literature that would offer mechanistic explanations for a change in spinal stiffness of individuals with LBP who report improvements in disability following spinal manipulation. The results from this review could then be used to develop a theoretical framework to guide future investigations in this area.

\section{Methods}

A scoping review is a form of review scholarship based on a framework for synthesizing available published literature on a given topic $[15,16]$. A scoping review, which allows more general questioning and exploration of the literature than a traditional systematic review [16, 17], is appropriate for developing an understanding of an emerging field.

\section{Research question}

An established scoping review methodology was used to collect and organize relevant information to examine the existing body of literature [15]. The review was guided by the following question: Are there potential mechanisms described in the literature that explain sudden changes in spinal stiffness in some, but not all individuals with LBP?

\section{Literature search strategy}

The review process followed the recent guideline of PRISMA (Preferred Reporting Items for Systematic Reviews and Meta-Analyses) and, particularly, the extension for Scoping Reviews (PRISMA-ScR) [18]. The peerreviewed literature was systematically searched in MEDLINE, CINAHL, and PubMed. The search terms included subject headings (MeSH terms) specific to each database and a combination of keywords relevant to SMT (including spinal manipulation and mobilization), spinal stiffness, lumbar spine, and mechanism (Additional file 1). The search period was restricted to studies published in the last two decades as the notion of spine mechanics only changing in SMT responders is less than a decade old and, thus, older studies are irrelevant for answering our research question. A manual review of articles' references was used as an additional data source. The search strategy was reviewed with the librarian in residence at the University of Alberta (Edmonton, Alberta, Canada).

\section{Study selection}

Eligibility criteria included: 1) publication in English; 2) quantification of lumbar spinal stiffness before and after an SMT; and 3) publication between January 1st, 2000 and June 10th, 2019 (date of the final literature search). Exclusion criteria included: 1) not using SMT as an intervention; and 2) only measuring cervical spinal stiffness. A pair of independent reviewers (PJ and IP) screened the search results in two rounds. All studies were first screened using titles and abstracts to identify relevant, possibly relevant, and irrelevant citations. Secondly, relevant and possibly relevant studies were screened in full text to determine eligibility against the above inclusion criteria. A third reviewer (GK) was involved to resolve disagreements. 


\section{Data extraction}

From the selected studies, data were extracted by 2 reviewers (PJ and IP), and any discrepancies were resolved after discussion. Extracted data from each included study contained: 1) first author and year of publication; 2) study design; 3) sample size and characteristics; 4) interventions; 5) spinal stiffness measurement and other variables/outcomes; and 6) main results.

Sentences that explained or speculated about the mechanism of SMT were manually extracted from the selected studies. Candidate sentences included wording such as "may be due / related / associated / explained / modified", "is believed", "was hypothesized", "may permit / allow / result / modify / increase / decrease/ facilitate / inhibit / explained" or "have been reported / shown to". If a sentence did not contain one of these phrases, but implied a potential mechanism underlying the effect of SMT, the sentence was also extracted. The extracted sentences were classified as either 1) a hypothesis or a re-statement from another study; or 2) a suggestion based on data from the study.

The extracted sentences were then pooled and categorized into mechanistic themes based on the context of the sentence. The sentences were analyzed within another full-text review in order to convey the original authors' intentions; then they were grouped together with respect to anatomical references (muscles, nerves, etc.) or measurements (mobility, pain, etc.). From these groupings, themes were created by 2 reviewers (PJ and IP) after discussion.

\section{Results}

\section{Overview of studies}

Our literature search identified 1929 studies. Two studies were manually added based on additional data sources (reviewer's knowledge of the literature and reference list of an included study). After removing the duplicates and two rounds of screening, 10 studies met the inclusion criteria and were then processed for sentence extraction (Fig. 1).

The descriptive characteristics of the 10 included studies are presented in Table 1. Three studies exclusively recruited participants with LBP $[9,23,26]$, two studies recruited healthy participants only [21, 25], and two studies recruited both participants with and without LBP $[10,20]$. Finally, three of the identified studies employed

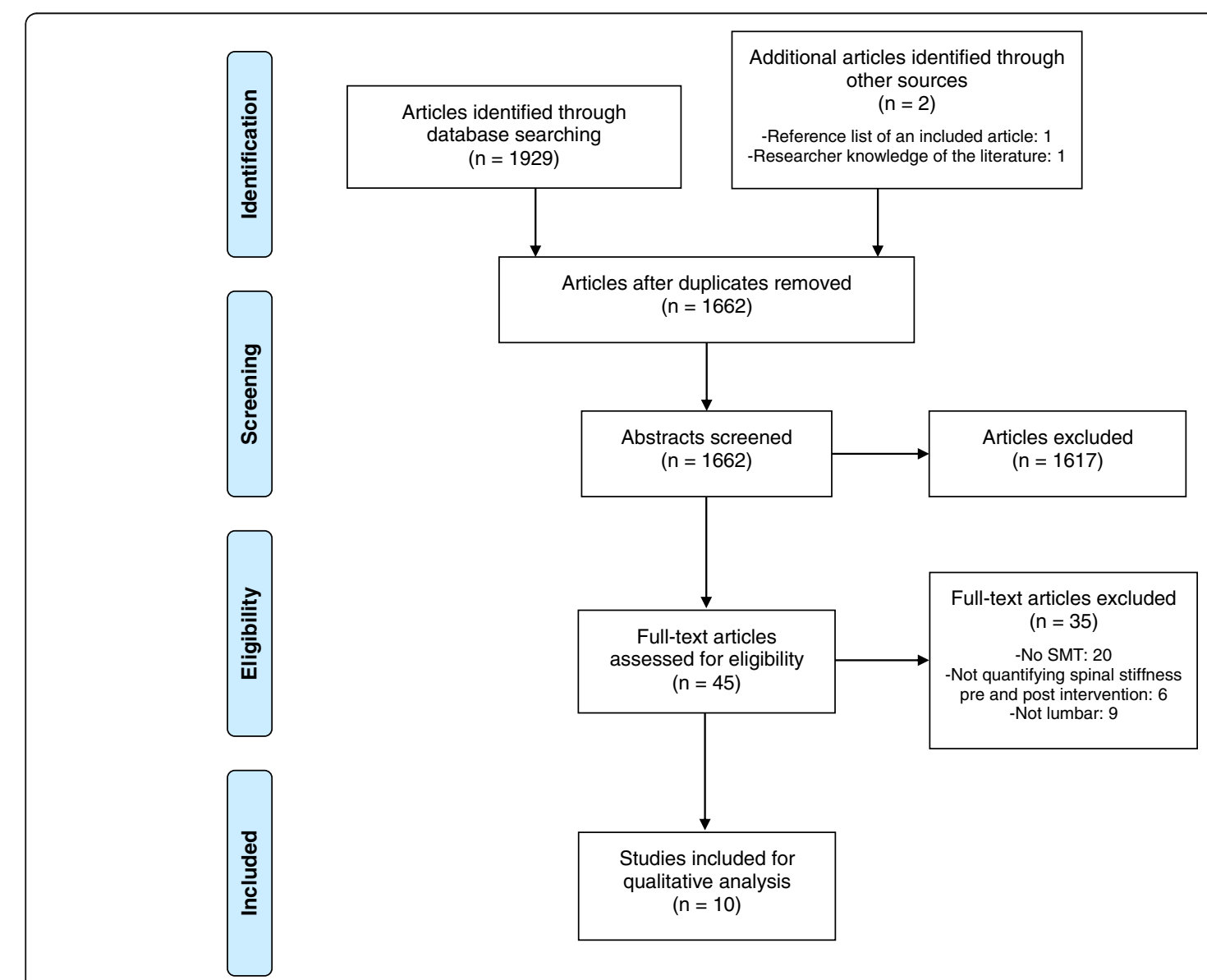

Fig. 1 PRISMA flow chart of the scoping review 


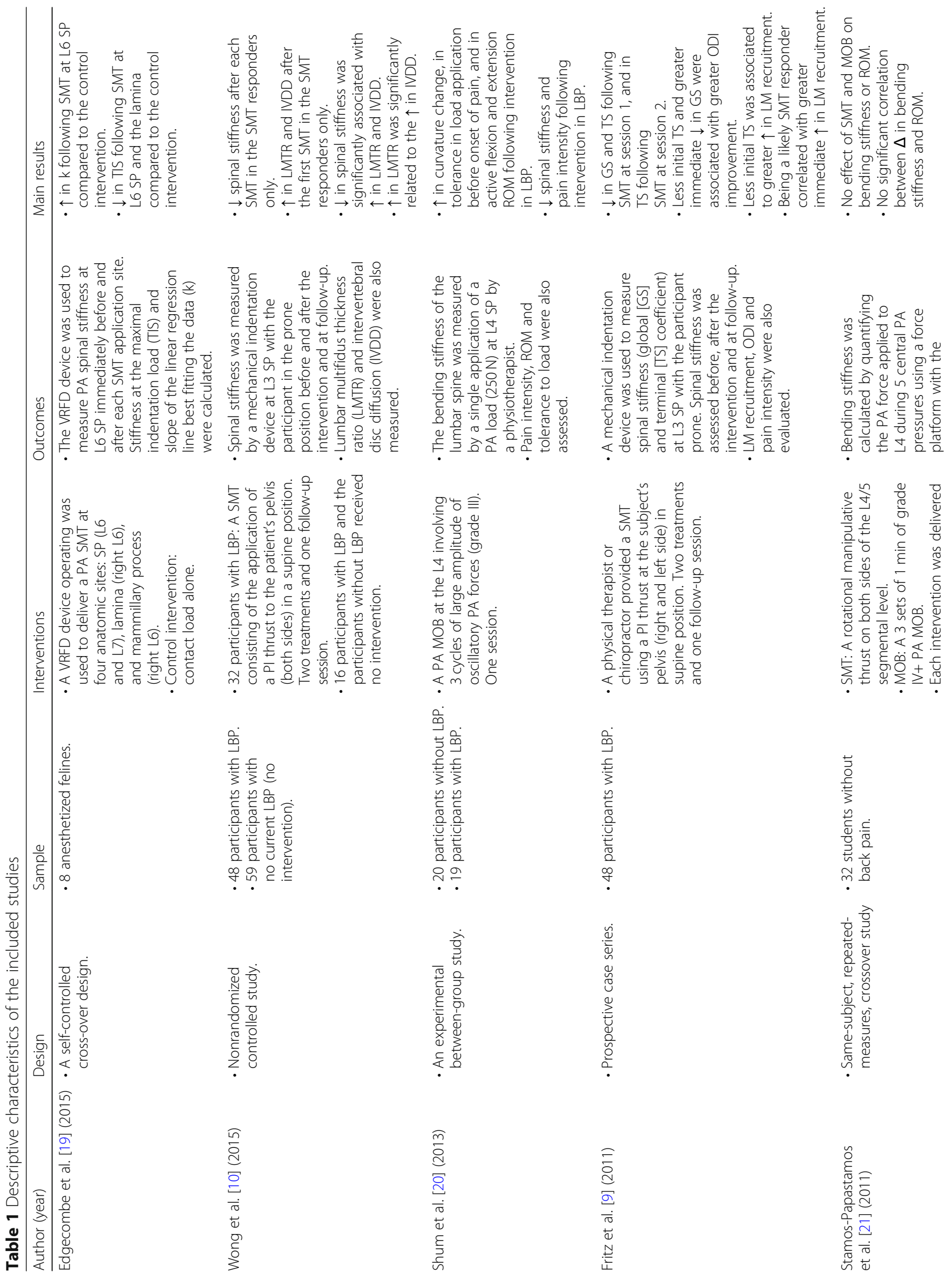




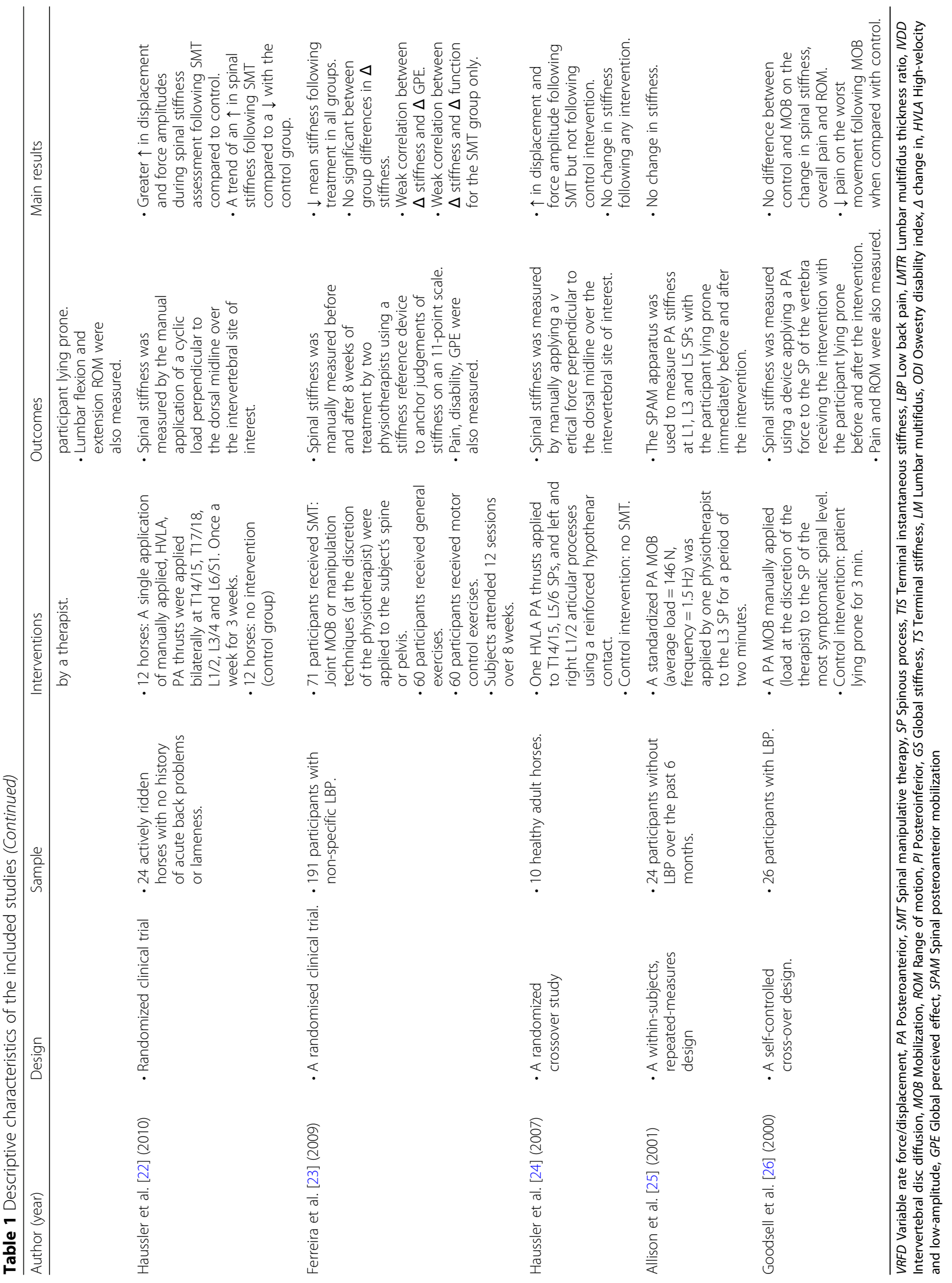


animal models (conscious horses [22, 24] and anesthetized felines [19]).

Importantly, the studies varied in the application of SMT. These differences included the use of spinal manipulation or mobilization at the discretion of the therapist [23], spinal manipulation and posteroanterior (PA) mobilization delivered by a clinician at L4/5 [21], lumbopelvic manipulation delivered by a clinician $[9,10]$, spinal manipulation delivered by a mechanical device with an external frame [19], PA mobilization delivered by a clinician at L3 [25], L4 [20], or SMT delivered to the most painful lumbar spinal level [26].

Regarding the measurement of spinal stiffness, most studies used a device with an external frame $[9,10,19$, $25,26]$, two studies used a handheld device [22, 24], and two studies calculated bending stiffness during PA mobilization [20, 21]. Ferreira et al. [23] used a reference device allowing clinicians to anchor their subjective impression of spinal stiffness to a reference measurement.

Finally, SMT effects on spinal stiffness greatly varied between studies. A decrease $[9,10,20]$ or no change $[21$, 25] in spinal stiffness following SMT were the most common results, while other studies revealed a nonstatistically different change when compared with another treatment or a control intervention [22-24, 26]. Different effects depending on the SMT location have also been reported by Edgecombe et al. [19].

\section{Mechanisms}

The reviewers were unable to identify any fully developed descriptions of mechanisms in the literature that would explain rapid changes in biomechanics following SMT. As such, we extracted sentences from the selected studies which illuminated possible mechanisms (Table 2). From these sentences, 7 mechanistic themes were identified: 1) change in muscle activity; 2) increase in mobility; 3) decrease in pain; 4) increase in pressure pain threshold; 5) change in spinal tissue behavior; 6) change in the central nervous system (CNS) or reflex pathways; and 7) correction of a vertebral dysfunction. While most studies expressed the potential mechanisms as hypotheses or restatements from one or multiple articles, the first 5 themes were derived from sentences taken from studies that collected data.

\section{Mechanistic themes}

\section{Theme 1: change in muscle activity}

Six studies suggested a link between a change in muscle activity or recruitment and the change in spinal stiffness $[9,10,20,22,23,25]$. These studies used different terms to refer to a change in muscle activity: change in lumbar multifidus (LM) thickness ratio [10], enhancement in LM recruitment [9], decrease in the muscle activity of the erector spinae [20], facilitation of muscle activity [9], presence of muscle relaxation [22, 25], correction of an altered motor function [22], and reduction in involuntary muscle activity [23]. Contrary to the other studies, Wong et al. [10] suggested that it is the change in muscle activity (i.e., LM thickness ratio) that is caused by a decrease in spinal stiffness and not the other way around. Two studies expressed this mechanism as an idea arising from the obtained data $[9,10]$. The study by Wong et al. [10] showed that SMT responders exhibit a decrease in spinal stiffness following SMT as well as an increase in the LM thickness ratio and that these changes are negatively associated. Fritz et al. [9] showed that less initial terminal stiffness is associated with a greater increase in LM recruitment and that likely being an SMT responder is correlated with a greater immediate increase in LM recruitment.

\section{Theme 2: increase in mobility}

A total of 6 studies suggested that changes in spinal or bending stiffness are associated with an increase in mobility following SMT. Similar to the change in muscle activity, different terms were used to describe this mechanism: increased segmental motion [10], improved spinal mobility [20, 22, 25], changes in lumbar range of motion (ROM) [21], improved spinal flexibility [22], and return of voluntary movement [23]. Four studies implied that the change in spinal stiffness may result in an increase in mobility $[10,20,23,25]$, while two studies pointed toward the opposite; i.e., that the change in mobility causes the spinal stiffness change [21, 22]. More specifically, Shum et al. [20] observed a significant increase in lumbar ROM following SMT as well as a significant decrease in spinal stiffness. In addition, a trend in an increase in spinal stiffness and a significant increase in dorsoventral displacement were reported by Haussler et al. [22]. Finally, Stamos-Papastamos et al. [21] observed no change in spinal stiffness (as measured via bending stiffness) and no change in lumbar ROM following their intervention, but still suggested a change in mobility as a potential mechanism of the observed SMT effect.

\section{Theme 3: decrease in pain}

A decrease in pain was reported as a potential mechanism by 5 studies $[20,21,23,25,26]$. However, two studies suggested that the change in spinal or bending stiffness is responsible for the decrease in pain [20,23], while the three others suggested that the decrease in pain is responsible for the change in spinal stiffness [21, $25,26]$. In line with this potential mechanism, Goodsell et al. [26] hypothesized that the non-significant change in spinal stiffness observed in their study was due to an insufficient change in pain following the treatment. Shum et al. [20] further suggested that the decrease in 
Table 2 Mechanistic themes identified based on the sentences used in the selected studies

\begin{tabular}{|c|c|c|}
\hline Mechanistic theme and studies & Specific sentences used in the studies & Related measurement \\
\hline \multicolumn{3}{|l|}{ Change in muscle activity } \\
\hline Wong et al. $[10]^{a}$ & $\begin{array}{l}\text { "decreases in spinal stiffness may permit increased disc } \\
\text { diffusion and increased segmental motion enabling } \\
\text { increased LM thickness ratios." }\end{array}$ & LM recruitment (thickness ratio) \\
\hline Shum et al. [20] & $\begin{array}{l}\text { "mechanical deformation of pain receptors of soft } \\
\text { tissues may elicit activity of the paraspinal muscles, } \\
\text { which will stiffen the motion segment ... in people } \\
\text { with back pain" } \\
\text { "The decrease in spinal stiffness and the increase in } \\
\text { spinal mobility after mobilization may also be due } \\
\text { to the decreased muscle activity of the erector spinae" }\end{array}$ & N/A \\
\hline Fritz et al. [9] $]^{a}$ & $\begin{array}{l}\text { "the effectiveness of SMT could relate to a mechanical } \\
\text { impact on spinal stiffness and subsequent neurophysiologic } \\
\text { consequences facilitating muscle activity" } \\
\text { "effects of SMT may be mediated by ... enhancement } \\
\text { in LM recruitment" }\end{array}$ & LM recruitment (thickness ratio) \\
\hline Haussler et al. [22] & $\begin{array}{l}\text { "Manual therapy techniques may also ... cause reflex } \\
\text { muscle relaxation, altered motor function" }\end{array}$ & N/A \\
\hline Ferreira et al. [23] & $\begin{array}{l}\text { "reductions in involuntary muscle activity associated } \\
\text { with resolution of pain may be responsible for the } \\
\text { reductions in spinal stiffness" }\end{array}$ & N/A \\
\hline Allison et al. [25] & "may be due to ... muscle relaxation" & N/A \\
\hline \multicolumn{3}{|l|}{ Increase in mobility } \\
\hline Wong et al. [10] & $\begin{array}{l}\text { "decreases in spinal stiffness may permit } \\
\text { increased ... segmental motion" }\end{array}$ & N/A \\
\hline Shum et al. [20] ${ }^{a}$ & $\begin{array}{l}\text { "changes in bending stiffness may be the mechanical } \\
\text { mechanism responsible for the ... improvement in } \\
\text { spinal mobility." }\end{array}$ & ROM \\
\hline Stamos-Papastamos et al. [21] $]^{\mathrm{a}}$ & $\begin{array}{l}\text { "some links were observed between changes in } \\
\text { stiffness and changes in lumbar ROM" }\end{array}$ & ROM \\
\hline Haussler et al. [22] ${ }^{a}$ & "Manual therapy techniques may also ... improved & Dorsoventral displacement \\
\hline
\end{tabular}

"applying a mechanical thrust (i.e. SMT) caused a

direct physiological increase in passive spinal mobility"

"indicative of producing a beneficial effect of increased passive spinal mobility or flexibility"

Ferreira et al. [23]

"it has been hypothesised that there is a relationship between spinal pain, reduced voluntary movement and abnormal spinal stiffness, and that restoration of normal spinal stiffness will result in a reduction of symptoms and a return of voluntary movement"

Allison et al. [25]

"Posteroanterior mobilization of the lumbar spine has been advocated as a treatment technique to restore spinal mobility on the basis that it will decrease spinal stiffness"

\section{Decrease in pain}

Shum et al. [20] ${ }^{\text {a }}$

"Large amplitude oscillations (grade III) may stimulate mechanoreceptors, leading to a decrease in pain" "changes in bending stiffness may be the mechanical mechanism responsible for the reduction in pain"

"It was hypothesized that a direct comparison of the 2 techniques [manipulation and mobilization] on the same asymptomatic subjects could possibly clarify the interaction of bending stiffness and ROM, without pain being present. Moreover, any changes on stiffness and ROM ... could not be due to pain relief."

"it has been hypothesised that there is a relationship 
Table 2 Mechanistic themes identified based on the sentences used in the selected studies (Continued)

\begin{tabular}{|c|c|c|}
\hline Mechanistic theme and studies & Specific sentences used in the studies & Related measurement \\
\hline & $\begin{array}{l}\text { of normal spinal stiffness will result in a reduction } \\
\text { of symptoms and a return of voluntary movement" } \\
\text { "change in stiffness was associated with back pain" } \\
\text { "changes in stiffness occur as symptoms improve in } \\
\text { patients with low back pain, and these changes } \\
\text { are not directly due to the application of spinal } \\
\text { manipulative therapy" }\end{array}$ & \\
\hline Allison et al. [25] & "may be due to changes in symptom response" & N/A \\
\hline Goodsell et al. [26] ${ }^{a}$ & $\begin{array}{l}\text { "Importantly, it has been theorized that hypomobile } \\
\text { spinal joints may occur in association with low-back } \\
\text { pain, and the stiffness of these joints may be altered } \\
\text { by use of manipulative therapy." } \\
\text { "the treatment did not produce a sufficient change in } \\
\text { pain for a change in stiffness to be detected" }\end{array}$ & Pain intensity (VAS) \\
\hline \multicolumn{3}{|c|}{ Increase in pressure pain threshold } \\
\hline Shum et al. [20] & $\begin{array}{l}\text { "The reduction in pain and stiffness .... may also be } \\
\text { due to changes in the pain threshold" }\end{array}$ & N/A \\
\hline Haussler et al. [22] ${ }^{a}$ & $\begin{array}{l}\text { "SMT also increased the amplitude of applied force, } \\
\text { indicative of increased tolerance to pressure" }\end{array}$ & Applied force \\
\hline Haussler et al. [24] & $\begin{array}{l}\text { "The increases in dorsoventral vertebral mobility and } \\
\text { the amount of applied pressure to the back after SMT" }\end{array}$ & Applied force \\
\hline \multicolumn{3}{|l|}{ Change in spinal tissue behavior } \\
\hline Edgecombe et al. [19] & $\begin{array}{l}\text { "the force applied during SMT application is } \\
\text { believed to affect the local spinal tissues" } \\
\text { "the observed increase in stiffness was the result of } \\
\text { viscoelastic change caused from insufficient fluid } \\
\text { recovery" }\end{array}$ & N/A \\
\hline Wong et al. [10] ${ }^{a}$ & $\begin{array}{l}\text { "decreases in spinal stiffness may permit increased } \\
\text { disc diffusion" }\end{array}$ & Intervertebral disc diffusion \\
\hline Allison et al. [25] ${ }^{\mathrm{a}}$ & $\begin{array}{l}\text { "Repeated loading of the spine causes creep and } \\
\text { relaxation of spinal connective tissues, changing the } \\
\text { resistance to the applied load. In some cases, micro- } \\
\text { failure of tight connective tissue structures may } \\
\text { decrease the resistance to movement and increase } \\
\text { the range of movement in a restricted spinal segment" } \\
\text { "the initial displacement under load may have changed, } \\
\text { reducing the length of the non-linear region of the force- } \\
\text { displacement curve or resulting in small movements of } \\
\text { the spine into more extension." }\end{array}$ & Stiffness measurement in multiple locations \\
\hline \multicolumn{3}{|c|}{ Change in the central nervous system or reflex pathways } \\
\hline Shum et al. [20] & $\begin{array}{l}\text { "The reduction in pain and stiffness ... may also be } \\
\text { due to changes in the ... and sympathetic nervous } \\
\text { response" } \\
\text { "the procedure may elicit activation of descending } \\
\text { inhibitory mechanisms" }\end{array}$ & N/A \\
\hline Fritz et al. [9] & $\begin{array}{l}\text { "An SMT force has been shown to stimulate peripheral } \\
\text { afferents, altering central nervous system (CNS) input, } \\
\text { and enhancing motoneuron excitability." }\end{array}$ & N/A \\
\hline Haussler et al. [22] & $\begin{array}{l}\text { "Manual therapy techniques may also stimulate peripheral } \\
\text { joint receptors and central nervous system pathways" }\end{array}$ & N/A \\
\hline Allison et al. [25] & $\begin{array}{l}\text { "reflex modulation of the sensory and motor } \\
\text { pathways ... may be modified" }\end{array}$ & N/A \\
\hline \multicolumn{3}{|c|}{ Correction of a vertebral dysfunction } \\
\hline Haussler et al. [24] & $\begin{array}{l}\text { "back stiffness is one of the primary clinical indicators } \\
\text { of vertebral dysfunction" }\end{array}$ & N/A \\
\hline
\end{tabular}


pain is due to the stimulation of mechanoreceptors during the PA mobilization or due to changes in the sympathetic nervous system. Finally, Ferreira et al. [23] suggested that the changes in spinal stiffness occur as symptoms improve in individuals with LBP, but that these changes are not directly due to the application of spinal manipulative therapy.

\section{Theme 4: increase in pressure pain threshold}

One study suggested that SMT generates an increase in pressure pain threshold, which would result in a decrease in spinal stiffness [20]. Moreover, the two studies involving horse models observed an increase in the amplitude of the applied force - until firm resistance at the end-range of motion in extension - following SMT which, according to the authors, would be indicative of increased tolerance to pressure [22, 24]. However, no change in spinal stiffness following SMT has been observed in those two studies.

\section{Theme 5: changes in spinal tissue behavior}

Edgecombe et al. [19] suggested that insufficient fluid recovery resulting in a change in the viscoelastic properties of the soft tissues would explain the increase in spinal stiffness following SMT observed in their study. In line with this, Allison et al. [25] suggested that repeated loading of the spine might cause creep and relaxation of the spinal connective tissues, which would change the resistance to the applied load and similarly the initial displacement under the applied load. Finally, Wong et al. [10] observed an increase in the intervertebral disc diffusion following SMT, but only in the participants classified as responders at follow-up. Responders also showed a decrease in lumbar spinal stiffness, which was, hence, negatively correlated with disc diffusion.

\section{Theme 6: changes in the CNS or reflex pathways}

Four studies hypothesized changes in the CNS or sensory and motor reflex pathways to be possible mechanisms for the changes in spinal stiffness and the decrease in pain following SMT [9, 20, 22, 25]. More specifically, Shum et al. [20] discussed potential changes in the sympathetic nervous system or the activation of descending inhibitory mechanisms. Additionally, Fritz et al. [9] suggested the facilitation of postsynaptic alpha motoneuron and cortico-motoneuron activity as well as improved cortical somatosensory integration as CNS changes that might result from SMT.

\section{Theme 7: correction of a vertebral dysfunction}

One study mentioned that an increase in spinal stiffness is one of the primary clinical indicators of vertebral dysfunction but did not discuss in more detail the definition of a vertebral dysfunction or how SMT would affect a vertebral dysfunction [24].

\section{Discussion}

To our knowledge, this is the first review to identify existing literature that would offer mechanistic explanations of a change in spinal mechanics following a spinal manipulation. Our review identified 7 themes of potential mechanisms from 10 selected studies: change in muscle activity, increase in mobility, decrease in pain, change in pressure pain threshold, change in spinal tissue behavior, change in the central nervous system or reflex pathways, and correction of a vertebral dysfunction. Although many ideas have been proposed about how spinal stiffness may change as a result of SMT, they have not yet been brought together in a systematic way for evaluation. As such, our scoping review is an attempt to understand and prioritize potential mechanisms for future research in this area.

As SMT has been shown to induce a rapid change in spine biomechanics in some, but not all, individuals with LBP, we will divide our discussion into those two parts, capturing: 1) themes that may explain this response directly; and 2) themes that are best described as secondary in that they most likely arise from direct mechanisms. To make this distinction, we assume that the force imparted by SMT is experienced by a number of spinal tissues directly. These would include bone, muscle, ligament, nerve, and others. As such, the themes that describe the immediate involvement of these tissues would be considered to be primary themes.

\section{Primary themes}

For the primary themes, we will limit our discussion to the possibility that the force imparted by SMT has a direct effect on the tissue of interest, resulting in a change in stiffness with no other systems involved.

\section{Muscle}

For this theme, we assume that the application of a direct force to the muscle will cause a change in the muscle that may impact post-SMT stiffness. Certainly, the application of direct force to a muscle can directly cause viscoelastic changes in the muscle that may result in stiffness alteration. The rapid application of force in SMT, however, would suggest a smaller viscoelastic effect than if the force were applied slowly [27]. When a muscle is pulled or extended rapidly as in the case of SMT, the time-dependent viscoelastic property of the muscle tissues hinders deformation and, thus, unlikely affects overall stiffness. Therefore, it is more likely that the muscle deformation may itself be the initiating event of other secondary mechanisms rather than a direct mechanism itself. 


\section{Spinal tissue}

Similar to muscle, applying a force on bones, ligaments, tendons, and joint capsules, etc. may directly result in a change in segmental stiffness due to the viscoelastic phenomenon. However, the contribution of each of these spinal tissues to the change in spinal stiffness will differ as the load experienced by each tissue is different during SMT [28]. While all spinal tissues may experience a load during SMT, not all are likely to deform via direct application of force; i.e., bone will not deform. Of these tissues, the intervertebral disc is the largest soft tissue structure in the spine and the one most likely to affect segmental stiffness when deformed. Forceful stretching of a disc caused by SMT could increase the disc height temporarily [29], which may impact stiffness. In addition, SMT is known to affect disc diffusion in SMT responders [10,30], and a degenerated disc alters lumbar spine segmental stiffness [31]. Assuming disc degeneration would affect its diffusion rate, we can make a connection that a change in disc diffusion following SMT may affect segmental stiffness. Given the observations from these various studies, the direct effects of SMT on the disc have more supporting evidence than other mechanisms with possible direct effects.

\section{Nerve}

It is unlikely that applying a force directly on the nerve would cause a direct change in spinal stiffness, although nerves can certainly experience such force directly. Nerve compression, direct pressure on a nerve, may cause pain, numbness, or muscle weakness, which may affect spinal stiffness; however, it would be unlikely that forces during SMT would achieve a magnitude that would cause this to happen and would most likely affect other tissues directly before the nerve would be impacted in this way.

\section{Secondary themes Muscle activity}

While it may be possible that the SMT force applied to the muscle can impact spinal stiffness directly, it is also possible that the nerve structures within the muscle are triggered by the deformation experienced by the muscle itself, which then initiate other downstream mechanisms. Deformation of muscle could activate paraspinal sensory neurons via stimulating muscle spindles [32, 33], which would increase muscle activity in return (e.g., increased LM recruitment), which is negatively correlated with spinal stiffness $[9,10]$. The only studies which measured muscle activity among the included studies found a change in LM thickness ratio following SMT using ultrasound imaging $[9,10]$. This supports the concept of muscle deformation being a secondary mechanism of stiffness change.

\section{Increased mobility}

An increase in mobility can only happen as a result of some change within the system occurring first. As such, this will be discounted as a primary theme. Put another way, whatever tissues are being affected, they subsequently allow a change in mobility or at least a theoretical change in mobility. Moreover, a change in spinal stiffness does not necessarily imply an increase in spinal mobility. Indeed, spinal stiffness represents the stiffness of underlying tissues throughout the application of load or, in other words, the tissue dynamics in response to the application of load $[34,35]$. It is, therefore, possible to observe a change in the spinal stiffness without any change in spine mobility.

\section{Pain}

A decrease in pain intensity and an increase in pressure pain threshold have been reported separately in two themes, but one could consider these potential mechanisms together. Although the work by Wong et al. (2016) shows how experimental pain (increased pain intensity) changes stiffness [36], it is uncertain if this is mediated by direct irritation of the muscles or if this effect is mediated by another system (e.g., nervous system). Interestingly, the result of being able to endure more pain is associated with decreased stiffness [20, 37]. Therefore, a linkage may exist between a decrease in stiffness resulting in decreased activation of nociceptors as current evidence supports that manual therapy immediately increases the local pressure pain threshold [38] and induces other pain-related changes $[39,40]$.

\section{Spinal tissue behavior}

None of the selected studies specifically mentioned the potential secondary effect of change in spinal tissues for stiffness change. However, evidence exists that the mechanical stress, such as caused by SMT, could stimulate or hinder non-nociceptive, mechanosensitive receptive nerves in spinal tissues, including skin, tendons, ligaments, facet joints, and intervertebral disc [41-44], which could influence CNS function.

\section{Nervous system}

Nerves can be stimulated by the deformation of the tissue in which they reside, which then begins a cascade of other events [32]. Although changes in the CNS or reflex pathways were not as often mentioned as the other mechanistic themes, they may be occurring concurrently with others (e.g., change in muscle activity and decrease in pain). Previous studies have shown a change in different parameters related to the Hoffman reflex following SMT, suggesting an inhibition of the spinal cord motoneuron pool [45-47], which leads to more excitable motoneurons or a lower recruitment threshold, e.g., an 
increased LM recruitment. In addition to stimulating the nervous system through other tissues affected by SMT, there is a suggestion that SMT may alter the nervous system itself through neuroplasticity [48]. Considering the immediate change in spinal stiffness that is possible following SMT, neuroplasticity as a mechanism for this response is unlikely.

\section{Correction of vertebral dysfunction}

Finally, one study stated that "back stiffness is one of the primary clinical indicators of vertebral dysfunction" implying that SMT "corrects" the vertebral dysfunction in the presence of spinal stiffness change [24]. Since the authors did not describe in more detail what they meant by "vertebral dysfunction" and did not mention how it can be "identified" and "corrected", this mechanism does not seem to be possible to be investigated.

\section{Future research}

A limited number of included studies indicate the lack of evidence on this topic. Moreover, none of the studies used a method justifying a cause-and-effect relation between SMT and lumbar spinal stiffness change that would promote one theme over another. These results suggest the need to create a working model for these changes, which can guide and prioritize future investigations. Future studies should focus on verifying the identified potential mechanisms; the priority may be on the mechanisms associated with changes in muscle activity and spinal tissue behavior, as they were the primary mechanistic themes that could affect spinal stiffness directly. There also needs to be more effort taken to understand how other measures of spinal function (e.g. EMG) could be helpful in understanding post-SMT changes. Understanding the mechanism(s) for lumbar spinal stiffness changes following SMT could provide valuable knowledge on understanding the LBP source and how it may be targeted with specific therapeutic interventions in the future.

\section{Limitations}

The main limitations of this scoping review are the small number of included studies and their heterogeneity. First, the interventions varied between studies, which might have influenced the effect on spinal stiffness and the other outcomes. For instance, spinal manipulation and mobilization have been shown to generate different physiological responses [49], and might therefore have different underlying mechanism(s) for changing spinal stiffness. Moreover, the varying inter-practitioner reliability of the manual intervention techniques [50] along with different measurement methods of spinal stiffness could have affected the outcomes as well. Studies were also excluded if not published in English, which may have resulted in missing relevant studies. As the earliest article within the search range was from almost 20 years ago, some proposed ideas are likely outdated.

\section{Conclusion}

This scoping review identified 7 themes of potential mechanisms for the change in lumbar spinal stiffness following SMT: change in muscle activity, increase in mobility, decrease in pain, change in pressure pain threshold, change in spinal tissue behavior, change in the central nervous system or reflex pathways, and correction of vertebral dysfunction. Our review suggests the need to systematically investigate these proposed mechanisms as the selected studies did not provide supporting data to verify the cause-and-effect relations, and to develop a theoretical framework for future research. Our review also provides insights on which suggested mechanisms may have research priorities in order to understand the change in spinal stiffness following SMT.

\section{Supplementary information}

Supplementary information accompanies this paper at https://doi.org/10. 1186/s12998-020-00304-X.

Additional file 1. List of the search terms and its subject headings.

\section{Abbreviations}

EMG: Electromyography; LBP: Low back pain; LM: Lumbar multifidus;

PA: Posteroanterior; PI: Posteroinferior; PRISMA: Preferred reporting items for systematic reviews and meta-analyses; SMT: Spinal manipulative therapy; ROM: Range of motion; CNS: Central nervous system; VRFD: Variable rate force/displacement; HVLA: High-velocity and low-amplitude; CPR: Clinical prediction rule; ODI: Oswestry disability index; GPE: Global perceived effect; $\Delta$ : Change in; MOB: Mobilization; SP: Spinous process; SPAM: Spinal posteroanterior mobilization

\section{Acknowledgements}

The authors would like to acknowledge Ms. Lydia Thorne, a public services librarian at John W. Scott Health Sciences Library (University of Alberta, Edmonton, Alberta, Canada) at the time, for her assistance in the literature search.

\section{Authors' contributions}

PJ and GK designed the study. PJ and IP completed the literature searches and data analysis. PJ, IP, AV, and GK contributed to the writing of the manuscript. All authors read and approved the final manuscript.

\section{Funding}

Not applicable.

\section{Availability of data and materials}

All data generated or analyzed during this study are included in this published article [and its supplementary information files].

Ethics approval and consent to participate

Not applicable.

Consent for publication

Not applicable.

Competing interests

The authors declare that they have no competing interests. 


\section{Author details}

${ }^{1}$ Faculty of Rehabilitation Medicine, University of Alberta, Corbett Hall, 8205 114 Street NW, Edmonton, Alberta T6G 2G4, Canada. ${ }^{2}$ Faculty of Rehabilitation Medicine, University of Alberta, Corbett Hall, 8205114 Street NW, Edmonton, Alberta T6G 2G4, Canada. ${ }^{3}$ Department of Mechanical Engineering, University of Alberta, Donadeo Innovation Centre for Engineering, 9211-116 Street, Edmonton, Alberta T6G 1H9, Canada. ${ }^{4}$ Department of Physical Therapy, University of Alberta, Corbett Hall, 8205 114 Street NW, Edmonton, Alberta T6G 2G4, Canada.

Received: 30 September 2019 Accepted: 16 March 2020 Published online: 23 March 2020

\section{References}

1. Hartvigsen J, Hancock MJ, Kongsted A, Louw Q, Ferreira ML, Genevay S, et al. What low back pain is and why we need to pay attention. Lancet. 2018;391:2356-67. https://doi.org/10.1016/S0140-6736(18)30480-X.

2. James SL, Abate D, Abate KH, Abay SM, Abbafati C, Abbasi N, et al. Global, regional, and national incidence, prevalence, and years lived with disability for 354 diseases and injuries for 195 countries and territories, 1990-2017: a systematic analysis for the global burden of disease study 2017. Lancet. 2018;392:1789-858. https://doi.org/10.1016/S0140-6736(18)32279-7.

3. Haldeman S, Kopansky-Giles D, Hurwitz EL, Hoy D, Mark Erwin W, Dagenais $\mathrm{S}$, et al. Advancements in the management of spine disorders. Best Pract Res Clin Rheumatol. 2012;26:263-80.

4. Rubinstein SM, Van MM, De BMR, Van TMW, van Middelkoop M, Assendelft WJ, et al. Spinal manipulative therapy for chronic low-back pain: An update of a Cochrane review. Spine (Phila Pa 1976). 2011;36:2-5. https://doi.org/10. 1097/BRS.0b013e3182197fe1.

5. Paige NM, Miake-Lye IM, Suttorp Booth M, Beroes JM, Mardian AS, Dougherty P, et al. Association of Spinal Manipulative Therapy with Clinical Benefit and Harm for acute low Back pain systematic review and metaanalysis. JAMA - J Am Med Assoc. 2017;90076:1451-60. https://doi.org/10. 1001/jama.2017.3086.

6. Rubinstein SM, De Zoete A, Van Middelkoop M, Assendelft WJJ, De Boer MR, Van Tulder MW. Benefits and harms of spinal manipulative therapy for the treatment of chronic low back pain: systematic review and meta-analysis of randomised controlled trials. BMJ. 2019;364:1689. https://doi.org/10.1136/bmj.l689.

7. Foster NE, Anema JR, Cherkin D, Chou R, Cohen SP, Gross DP, et al. Prevention and treatment of low back pain: evidence, challenges, and promising directions. Lancet. 2018;391:2368-83. https://doi.org/10.1016/ S0140-6736(18)30489-6.

8. Oliveira CB, Maher CG, Pinto RZ, Traeger AC, Lin CWC, Chenot JF, et al Clinical practice guidelines for the management of non-specific low back pain in primary care: an updated overview. Eur Spine J. 2018;27:2791-803. https://doi.org/10.1007/s00586-018-5673-2.

9. Fritz JM, Koppenhaver SL, Kawchuk GN, Teyhen DS, Hebert JJ, Childs JD, et al. Preliminary investigation of the mechanisms underlying the effects of manipulation: exploration of a multivariate model including spinal stiffness, multifidus recruitment, and clinical findings. Spine (Phila Pa 1976). 2011;36: 1772-81. https://doi.org/10.1097/BRS.0b013e318216337d.

10. Wong AYL, Parent EC, Dhillon SS, Prasad N, Kawchuk GN. Do participants with low back pain who respond to spinal manipulative therapy differ biomechanically from nonresponders, untreated controls or asymptomatic controls? Spine (Phila Pa 1976). 2015;40:1329-37. https://doi.org/10.1097/ BRS.0000000000000981.

11. Koppenhaver SL, Fritz JM, Hebert JJ, Kawchuk GN, Childs JD, Parent EC, et al. Association between changes in abdominal and lumbar Multifidus muscle thickness and clinical improvement after spinal manipulation. J Orthop Sport Phys Ther. 2011;41:389-99. https://doi.org/10.2519/jospt.2011.3632.

12. Skouen JS, Grasdal AL, Haldorsen EMH, Ursin H. Relative costeffectiveness of extensive and light multidisciplinary treatment programs versus treatment as usual for patients with chronic low back pain on long-term sick leave: Randomized controlled study. Spine (Phila Pa 1976). 2002;27:901-9.

13. Lederman NG, Lederman JS. What is a theoretical framework? A practical answer. J Sci Teacher Educ. 2015;26:593-7.

14. Taylor DN. A theoretical basis for maintenance spinal manipulative therapy for the chiropractic profession. J Chiropr Humanit. 2011;18:74-85. https:// doi.org/10.1016/j.echu.2011.07.001.
15. Peterson J, Pearce PF, Ferguson LA, Langford CA. Understanding scoping reviews: definition, purpose, and process. J Am Assoc Nurse Pract. 2017;29: 12-6. https://doi.org/10.1002/2327-6924.12380.

16. Munn Z, Peters MDJ, Stern C, Tufanaru C, McArthur A, Aromataris E. Systematic review or scoping review? Guidance for authors when choosing between a systematic or scoping review approach. BMC Med Res Methodol. 2018;18:143. https://doi.org/10.1186/s12874-018-0611-x.

17. Moher D, Stewart L, Shekelle P. All in the family: systematic reviews, rapid reviews, scoping reviews, realist reviews, and more. Syst Rev. 2015;4:183. https://doi.org/10.1186/s13643-015-0163-7.

18. Tricco AC, Lillie E, Zarin W, O'Brien KK, Colquhoun H, Levac D, et al. PRISMA extension for scoping reviews (PRISMA-SCR): checklist and explanation. Ann Intern Med. 2018;169:467-73. https://doi.org/10.7326/M18-0850.

19. Edgecombe TL, Kawchuk GN, Long CR, Pickar JG. The effect of application site of spinal manipulative therapy (SMT) on spinal stiffness. Spine J. 2015; 15:1332-8. https://doi.org/10.1016/j.spinee.2013.07.480.

20. Shum GL, Tsung BY, Lee RY. The immediate effect of Posteroanterior mobilization on reducing Back pain and the stiffness of the lumbar spine. Arch Phys Med Rehabil. 2013;94:673-9. https://doi.org/10.1016/j.apmr.2012.11.020.

21. Stamos-Papastamos N, Petty NJ, Williams JM. Changes in bending stiffness and lumbar spine range of movement following lumbar mobilization and manipulation. J Manip Physiol Ther. 2011;34:46-53. https://doi.org/10.1016/j. jmpt.2010.11.006.

22. Haussler KK, Martin CE, Hill AE. Efficacy of spinal manipulation and mobilisation on trunk flexibility and stiffness in horses: a randomised clinical trial. Equine Vet J. 2010;42:695-702

23. Ferreira ML, Ferreira PH, Latimer J, Herbert RD, Maher C, Refshauge K. Relationship between spinal stiffness and outcome in patients with chronic low back pain. Man Ther. 2009;14:61-7. https://doi.org/10.1016/j.math.2007.09.013.

24. Haussler KK, Hill AE, Puttlitz CM, Mcllwraith CW. Effects of vertebral mobilization and manipulation on kinematics of the thoracolumbar region. Am J Vet Res. 2007:68:508-16.

25. Allison G, Edmonston S, Kiviniemi K, Lanigan $H$, Simonsen AV, Walcher $S$, et al. Influence of standardized mobilization on the posteroanterior stiffness of the lumbar spine in asymptomatic subjects. Physiother Res Int. 2001;6: 145-56. https://doi.org/10.1002/pri.223.

26. Goodsell M, Lee M, Latimer J. Short-term effects of lumbar posteroanterior mobilization in individuals with low-back pain. J Manip Physiol Ther. 2000; 23:332-42. https://doi.org/10.1067/MMT.2000.106867.

27. Holzapfel GA. Biomechanics of soft tissue. In: Lemaitre J, editor. Handbook of materials behavior models. San Diego: Academic Press; 2001. p. 1057-71. https://doi.org/10.1016/B978-012443341-0/50107-1.

28. Funabashi M, Nougarou F, Descarreaux M, Prasad N, Kawchuk GN. Spinal Tissue Loading Created by Different Methods of Spinal Manipulative Therapy Application. Spine (Phila Pa 1976). 2017;42:635-43. https://doi.org/ 10.1097/BRS.0000000000002096.

29. Vieira-Pellenz F, Oliva-Pascual-Vaca Á, Rodriguez-Blanco C, Heredia-Rizo AM, Ricard F, Almazán-Campos G. Short-term effect of spinal manipulation on pain perception, spinal mobility, and full height recovery in male subjects with degenerative disk disease: a randomized controlled trial. Arch Phys Med Rehabil. 2014;95:1613-9.

30. Wong AYL, Parent EC, Dhillon SS, Prasad N, Samartzis D, Kawchuk GN. Differential patient responses to spinal manipulative therapy and their relation to spinal degeneration and post-treatment changes in disc diffusion. Eur Spine J. 2019;28:259-69. https://doi.org/10.1007/s00586-018-5851-2.

31. Zirbel SA, Stolworthy DK, Howell LL, Bowden AE. Intervertebral disc degeneration alters lumbar spine segmental stiffness in all modes of loading under a compressive follower load. Spine J. 2013;13:1134-47. https://doi.org/10.1016/j.spinee.2013.02.010.

32. Pickar JG. Neurophysiological effects of spinal manipulation. Spine J. 2002;2: 357-71. https://doi.org/10.1016/s1529-9430(02)00400-x.

33. Pickar JG, Bolton PS. Spinal manipulative therapy and somatosensory activation. J Electromyogr Kinesiol. 2012;22:785-94. https://doi.org/10.1016/j. jelekin.2012.01.015.

34. Wong AYLL, Kawchuk GN. The clinical value of assessing lumbar Posteroanterior segmental stiffness: a narrative review of manual and instrumented methods. PM R. 2017;9:816-30. https://doi.org/10.1016/j.pmrj.2016.12.001.

35. Brown BT, Blacke A, Carroll V, Graham PL, Kawchuk G, Downie A, et al. The comfort and safety of a novel rolling mechanical indentation device for the measurement of lumbar trunk stiffness in young adults. Chiropr Man Ther. 2017;25:1-10. 
36. Wong AYLL, Parent EC, Prasad N, Huang C, Chan KM, Kawchuk GN. Does experimental low back pain change posteroanterior lumbar spinal stiffness and trunk muscle activity? A randomized crossover study. Clin Biomech. 2016;34:45-52. https://doi.org/10.1016/j.clinbiomech.2016.03.006.

37. Snodgrass SJ, Rivett DA, Sterling M, Vicenzino B. Dose optimization for spinal treatment effectiveness: a randomized controlled trial investigating the effects of high and low mobilization forces in patients with neck pain. J Orthop Sport Phys Ther. 2014;44:141-52. https:/doi.org/10.2519/jospt.2014.4778.

38. Voogt L, de Vries J, Meeus M, Struyf F, Meuffels D, Nijs J. Analgesic effects of manual therapy in patients with musculoskeletal pain: a systematic review. Man Ther. 2015;20:250-6. https://doi.org/10.1016/j.math.2014.09.001.

39. Bialosky JE, Bishop MD, Robinson ME, Zeppieri G, George SZ. Spinal manipulative therapy has an immediate effect on thermal pain sensitivity in people with low Back pain: a randomized controlled trial. Phys Ther. 2009; 89:1292-303. https://doi.org/10.2522/pti.20090058.

40. Randoll C, Gagnon-Normandin V, Tessier J, Bois S, Rustamov N, O'Shaughnessy J, et al. The mechanism of back pain relief by spinal manipulation relies on decreased temporal summation of pain. Neuroscience. 2017;349:220-8.

41. Gillette RG. A speculative argument for the coactivation of diverse somatic receptor populations by forceful chiropractic adjustments. A review of the neurophysiological literature. Man Med. 1987;3:1-14 https://www.scopus. com/inward/record.uri?eid=2-s2.0-0023192821\&partnerlD=40\&md5=cd0003 b43070cfa287f9527e3b4a1940.

42. Buerger AA. Experimental neuromuscular models of spinal manual techniques. Man Med. 1983:1:10-7 https://www.scopus.com/inward/record.uri?eid=2-s2.00020991480\&partnerlD=40\&md5=ec1 b4c8dfb43df87e177c3e1 bbff6100.

43. Eldred $\mathrm{E}$, Hutton RS, Smith JL. Nature of the persisting changes in afferent discharge from muscle following its contraction. Prog Brain Res. 1976;44(C): 157-70.

44. lanuzzi A, Khalsa PS. Comparison of human lumbar facet joint capsule strains during simulated high-velocity, low-amplitude spinal manipulation versus physiological motions. Spine J. 2005;5:277-90.

45. Dishman JD, Bulbulian R. Spinal reflex attenuation associated with spinal manipulation. Spine (Phila Pa 1976). 2000;25:2519-25.

46. Niazi IK, Türker KS, Flavel S, Kinget M, Duehr J, Haavik H. Changes in H-reflex and V-waves following spinal manipulation. Exp Brain Res. 2015;233:116573. https://doi.org/10.1007/s00221-014-4193-5.

47. Ginanneschi F, Dominici F, Milani P, Biasella A, Rossi A, Mazzocchio R. Changes in the recruitment curve of the soleus $\mathrm{H}$-reflex associated with chronic low back pain. Clin Neurophysiol. 2007;118:111-8. https://doi.org/10, 1016/j.clinph.2006.09.024

48. Boal RW, Gillette RG. Central neuronal plasticity, low back pain and spinal manipulative therapy. J Manip Physiol Ther. 2004;27:314-26.

49. Pagé I, Biner É, Descarreaux M. Vertebral displacements and muscle activity during manual therapy: distinct behaviors between spinal manipulation and mobilization. J Manip Physiol Ther. 2018;41:753-61. https://doi.org/10.1016/j. jmpt.2018.07.004.

50. Bishop MD, Torres-Cueco R, Gay CW, Lluch-Girbés E, Beneciuk JM, Bialosky JE. What effect can manual therapy have on a patient's pain experience? Pain Manag. 2015;5:455-64

\section{Publisher's Note}

Springer Nature remains neutral with regard to jurisdictional claims in published maps and institutional affiliations.

Ready to submit your research? Choose BMC and benefit from:

- fast, convenient online submission

- thorough peer review by experienced researchers in your field

- rapid publication on acceptance

- support for research data, including large and complex data types

- gold Open Access which fosters wider collaboration and increased citations

- maximum visibility for your research: over $100 \mathrm{M}$ website views per year

At BMC, research is always in progress.

Learn more biomedcentral.com/submissions 